\title{
Is a Rose Always a Rose? The Role of Social Category Exemplar Change in Attitude Stability and Attitude-Behavior Consistency
}

\author{
Tiffiny L. Sia, Charles G. Lord, \\ Kenneth A. Blessum, and Christopher D. Ratcliff \\ Texas Christian University
}

\author{
Mark R. Lepper \\ Stanford University
}

\begin{abstract}
Three experiments tested whether changes in social category exemplars affect attitude stability, attitude-behavior consistency, or attitude change. In Experiment 1, participants displayed greater attitude stability across 1 month, in several social categories, when they named the same rather than different exemplars. In Experiment 2, participants displayed greater attitude-behavior consistency toward each of 2 social categories when they named the same rather than different exemplars at behavior assessment and at attitude assessment. Participants who named a more likable exemplar behaved more positively, and those who named a less likable exemplar behaved more negatively, than their initial attitudes predicted. In Experiment 3, participants changed their attitudes in the predicted direction after estimating the height of an exemplar who was either more or less likable than the one they had earlier named. The results are interpreted as consistent with recent theory and research on attitude introspection, the matching hypothesis, and models of social judgment.
\end{abstract}

According to Gertrude Stein's famous dictum, A rose is a rose is a rose. When it comes to attitude-behavior consistency toward social categories such as politicians, gay men and lesbians, televangelists, talk show hosts, foreign leaders, and rock musicians, however, both classic and current studies have suggested that life is not always so simple. The present study asked whether attitudes toward social categories fluctuate across time and situation depending on which category member (exemplar) comes to mind; whether attitude-behavior consistency is greater when the same, rather than a different, category exemplar comes to mind at the time behavior is assessed as at the time attitude was assessed; whether it is possible from knowing whether a more positive or more negative exemplar came to mind to predict the direction of attitude-behavior inconsistency; and whether the exemplar that comes to mind changes attitudes.

As early as 1934, Richard LaPiere suggested that attitudebehavior consistency might depend in part on how a social category is represented. LaPiere toured the southwestern United States with a Chinese couple at a time when the media were reporting intense anti-Oriental attitudes. To LaPiere's surprise, his Chinese friends were served courteously at all but 1 of 251 restaurants and hotels. Subsequently, LaPiere sent an attitude questionnaire to the proprietors of these and other establishments. Of the respondents, including those at 128 of the places that LaPiere and his friends had visited, more than $90 \%$ said they had such negative attitudes that they would refuse to serve "'members of the Chinese race.' In commenting on this striking

Tiffiny L. Sia, Charles G. Lord, Kenneth A. Blessum, and Christopher D. Ratcliff, Department of Psychology, Texas Christian University; Mark R. Lepper, Department of Psychology, Stanford University.

Corresponidence concerning this article should be addressed to Charles G. Lord, Department of Psychology, Texas Christian University, Fort Worth, Texas 76129. Electronic mail may be sent via the Internet to c.lord@tcu.edu. example of attitude-behavior inconsistency, LaPiere (1934) noted that answers on an attitude questionnaire constitute a "verbal response to a symbolic situation" (p. 230) that might not correspond with the actual situation in which behavior occurs. LaPiere speculated that the proprietors did not behave in line with their attitudes at least in part because his well-dressed, cultured friends did not match what the proprietors had in mind as "members of the Chinese race"' when they completed the attitude questionnaire.

Six years later, in 1940, Solomon Asch addressed the "symbolic situation"' more explicitly. Asch asked students to rank the intelligence, social usefulness, conscientiousness, stability of character, and idealism of ten professions, one of which was politics. To influence these rankings, Asch led some students to believe that 500 of their peers had, on average, ranked politics 10th (last) on all 5 dimensions. Other students were led to believe that the 500 peers had ranked politics first. The purported peer rankings had a large influence on students' own rankings. Those who thought their peers had ranked politics last, for instance, themselves ranked politics between 8th and 9th on social usefulness, whereas those who thought their peers had ranked politics first gave it a rank of 4 th among a group of professions that included business, engineering, law, music, teaching, and medicine.

When Asch interviewed the students, they claimed that they had not been swayed by the peer ratings nor had they conformed to them. Instead, Asch argued, students in the different experimental conditions had different politicians in mind. When they learned that their peers had ranked politics first, they thought about intelligent, idealistic statespersons such as President Franklin D. Roosevelt. When they learned that their peers had ranked politics last, they thought about corrupt party hacks such as Boss Tweed, who ran the infamous Tammany Hall. Asch concluded that the students had been influenced indirectly rather than directly. When the peer rankings brought Roosevelt and 
other great statespersons to mind, calling politics a noble profession seemed reasonable. When the peer rankings brought Boss Tweed and others of his type to mind, disparaging the profession seemed just as reasonable. The students were not aware that different politicians might have come to mind had they been in the other condition, so they explicitly denied that their attitudes had been influenced. As Asch (1940) observed, "the process under investigation entails a change in the object of judgment, rather than in the judgment of the object" (p. 458).

More recent investigations also suggest that attitudes toward social categories depend at least in part on which category members come to mind as a symbolic representation of the category. In one study, male students reported their attitudes toward homosexuals and described what they had in mind as the "typical" homosexual (Lord, Lepper, \& Mackie, 1984). Many students, for instance, said they had in mind someone who was sensitive and nonathletic. Approximately 1 month later, the same students expressed their willingness to host or interact with each of two visiting transfer students, one of whom "happened" to have led a gay rights rally in New York City. For some of the students, the visitor was said to have all the characteristics they had attributed to a "typical" homosexual. For other students, the visitor was opposite the "typical"' homosexual (but neither more nor less likable) on some important characteristics. He was, for instance, very athletic. Students' attitudes toward the category "homosexuals" predicted their willingness to interact with the visiting category member significantly better when he matched, rather than mismatched, what they said they had in mind when they completed the initial attitude questionnaire. Similar differences occur when the behavioral target matches, rather than mismatches, what the attitude holder has in mind regarding physical appearance (Lord, Desforges, Ramsey, Trezza, \& Lepper, 1991) or regarding belonging to one, rather than another, subcategory within a larger category (Ramsey, Lord, Wallace, \& Pugh, 1994).

The LaPiere (1934), Asch (1940), and Lord et al. (1984) studies suggested several previously untested hypotheses about attitude-behavior consistency toward social categories. First, for people who hold positive or negative attitudes toward a social category, either the same or different category exemplars might come to mind at different times when they assess their own attitudes. In research on natural-object categories (e.g., vegetables), Bellezza (1984) established that people have a .69 probability of naming the same category exemplar (e.g., carrots) when asked to do so twice, 1 month apart. No previous research has addressed the probability of naming the same exemplar at different times for social categories. Although Asch solicited information that included category exemplars, LaPiere did not, and Lord et al. simply asked about the characteristics of a "typical" exemplar rather than having students name specific ones.

Second, attitudes toward social categories might be less stable over time when different, rather than the same, category members come to mind. Work on introspection has shown that "people often have a large, conflicting 'data base' relevant to their attitudes on any given topic, and the attitude they have at any given time depends on the subset of these data to which they attend" (Wilson \& Hodges, 1992, p. 38; see also Salancik \& Conway, 1975; Tesser, 1978; Wilson, Lisle, \& Kraft, 1990; Wil- son, Lisle, \& Schooler, 1990; Zanna \& Rempel, 1988). Work on assimilation and contrast effects has shown that "evaluation of a target is based on the information that is included in the temporary representation that individuals construct of it" (Schwarz \& Bless, 1992a, p. 219; see also Schwarz \& Bless, $1992 b$ ). Work on the social judgment model (Smith \& Zarate, 1992) similarly has shown that people make judgments about social categories by comparing a given stimulus person with whichever category exemplars come to mind (Smith \& Zarate, 1990; Zarate \& Smith, 1990). Nonetheless, work on introspection has not specifically addressed changes in category exemplars as part of the so-called large, conflicting database behind attitudes, nor has work on assimilation and contrast or the social judgment model specifically addressed their relevance to attitude stability and attitude-behavior consistency.

Third, attitudes toward a social category might be less predictive of behavior toward the category when different exemplars come to mind at the time when subsequent behavior is assessed than came to mind at the time when the initial attitude was assessed. Again, previous work has shown that attitudes do sometimes change spontaneously (Alwin, 1976; Fishbein, 1976; Schuman \& Johnson, 1967; Schwartz \& Tessler, 1972; Thurstone, 1931; Wicker, 1969); that attitudes are more likely to change spontaneously when the delay between attitude measurements is long, rather than short (Schwartz, 1978); that being reminded of a specific corrupt politician erodes trust in politicians in general (Schwarz \& Bless, 1992b); and that being reminded of successful African Americans increases White students' awareness of racial discrimination (Bodenhausen, Schwarz, Bless, \& Wänke, 1995). No previous study, however has examined the role of spontaneous exemplar change in attitude instability, much less in attitude-behavior inconsistency.

For social categories (and possibly for some nonsocial categories), it seems possible that Asch (1940) was correct. When people think of a different politician, one might come to mind that significantly alters the way they represent the category symbolically (Smith, 1992, in press). A different exemplar coming to mind presumably increases the probability of associating a differently liked person with the category. Although it is not impossible for people to change their opinions of the same exemplar (e.g., liking President Roosevelt one month and disliking him the next), differential liking seems more likely when the exemplar itself changes (e.g., from President Roosevelt to Boss Tweed).

An examination of social category exemplars as they pertain to attitude stability and attitude-behavior consistency also has the potential to answer several previously unexplored research questions. Are some individuals more likely than others to change the exemplars they have in mind across all social categories, or is spontaneous exemplar change category-specific? Does it matter whether the individual thinks of the exemplar first or the category first, or do the two thoughts go hand in hand, as theories of spreading activation suggest (e.g., Collins \& Loftus, 1975 ) ? Do social category exemplars have a hierarchical structure? When people think of a different exemplar than they had previously, for instance, is it likely to be the one they would have named second, had they been asked? Also, is it possible for people to "forget" temporarily a well-known social category 
exemplar but for that one to come to mind first on a later occasion?

Finally, perhaps most important, does knowing about changes in social category exemplars increase the precision of predicting behavior from attitudes? If we know, for instance, that news events have made salient for an individual the one politician that she or he most admires, might we expect that individual to treat politicians more positively than her previously expressed attitude (when she or he was thinking of a different politician) would have predicted? Conversely, if a more negative exemplar comes to mind, might the individual behave more negatively toward politicians than her previously expressed attitude would have led us to expect? Previous studies have predicted when behaviors would be consistent versus inconsistent with attitudes, but they have not attempted to predict the direction of inconsistency.

\section{Experiment 1: Social Category Exemplars and Attitude Stability}

In the first experiment, we examined the relationship between the stability of social category exemplars and the stability of attitudes. Experiment 1 was necessary because if exemplar stability were not related to attitude stability, then there would be no point in conducting a second experiment in which exemplar instability was expected to reduce attitude-behavior consistency.

\section{Method}

\section{Participants}

One hundred eighty-three undergraduates ( 82 men and 101 women) participated for course credit. Data from 18 of the students (10 men and 8 women) were not included in the analyses because they did not complete the materials appropriately. Seventeen students were randomly assigned to a control condition. One hundred forty-eight students were randomly assigned to the experimental condition. Gender did not affect the results.

\section{Procedure}

Students in the control condition provided their attitudes toward seven social categories and one natural-object category at two times, 1 month apart. The purpose of the control condition was to provide a baseline measure of how much attitude stability could be expected if students were never asked about exemplars. The control condition thus tested whether results from the experimental condition reflected an artificially high or low level of attitude stability created by the experimental procedure. Students in the experimental condition, in contrast, completed an initial questionnaire in one session, made liking ratings in a second session, and completed a second questionnaire in a third session.

Initial questionnaire. In the experimental condition, students participated in an "initial questionnaire" session, in which they were asked to name the first specific exemplar that came to mind for each of eight categories, seven of which were social categories and one of which was a natural-object category (vegetables) that was included as a comparison to previous research.

The seven social categories were politicians, televangelists, talk show hosts, foreign leaders, homosexuals, rock musicians, and stand-up comics. Students also provided their general attitudes toward each category on a scale ranging from -5 (very negative) to 5 (very positive). Order was counterbalanced so that, for each category, half of the students first indicated their eight attitudes and then named their eight first exemplars, whereas the other half first named their eight exemplars and then gave their eight attitudes. Order effects thus tested whether the procedure of asking people to name category exemplars prior to reporting their attitudes might induce a decision process different from what occurs when people simply assess their attitudes.

All instructions and questions were shown on overhead transparencies and were also read out loud. For each question, students were given 10 $\mathrm{s}$ to provide their answer. The instructions indicated that a category exemplar is "the first specific example that comes to mind." Next (after providing eight attitudes and eight exemplars), students were asked to name any other exemplars that they thought might come to mind spontaneously for the categories. These additional category members were requested to find likely "substitutes" that the student might spontaneously associate most strongly with the category at a later time. The students were given $30 \mathrm{~s}$ to name as many other exemplars as they thought might occur to them for each category. They were wamed, however, that the task was "not a test of how many examples you can name. We are not looking for unusual examples of the category either If you were to think of the category on several different occasions, would there be any other specific examples that might come to mind?"

The students were then reminded of the dates for their second session. They were also told that another experimenter would conduct the second session, which would involve a brief unrelated experiment.

Liking ratings. In the second session, approximately 2 weeks later, a different experimenter claimed to be studying how well liked various well-known objects and people are. The students were asked to sign a consent form that was formatted differently from the one used in the initial questionnaire to convince them that the experiments were indeed separate and unrelated. These precautions were necessary both because we wished to circumvent motives to appear consistent and because specific politicians might be rated as of very different likability among diverse attitude objects in comparison with other politicians (Biernat \& Manis, 1994). Students were given a list of 150 well-known objects and people (e.g., Rice Krispies, sports cars, Bill Clinton). Each student's list was tailored to include 20 of the exemplars that the individual had provided for some of the social categories on the initial questionnaire. Students rated how much they liked each object or person on a scale ranging from -5 (not very much) to 5 (very much).

The categories included for each student were chosen on the basis of three criteria. First, the student's general attitude toward the category could not have been neutral. Second, the student must have given at least two additional spontaneous exemplars (in addition to the first exemplar), so that there was a chance the student might change his or her exemplar. Third, one or more of the exemplars given had to have been differentially liked by at least 2 points on a -5 to 5 rating scale according to pretest likability ratings that were provided by 70 other students who did not participate in the present studies. Every student met these criteria for at least four categories. Because all students met the criteria for the category "politicians," the politician exemplars were included on the list for every participant. The other categories were chosen on an individual basis for each student according to the aforementioned criteria.

The selected exemplars were randomly dispersed throughout the list. In pretesting these materials on 11 graduate students, it was determined that as many as 20 of their own category exemplars could be included on a list of 150 names without students being aware, even when asked, that there was any connection between the list and the earlier questionnaire.

After students had completed the liking ratings, the experimenter thanked them for participating. Then, to make the session seem unrelated to earlier or later sessions, we falsely debriefed students about this "unrelated" experiment's hypothesis. The bogus hypothesis was that 
well-known objects and people would be better liked than lesser known objects and people. Students were then reminded about the dates for the third session with the original experimenter.

Second questionnaire. In the third session, approximately 1 month after the initial questionnaire, the same procedure was followed as in the initial questionnaire. Independent of order on the initial questionnaire, students were randomly assigned to provide either attitudes first or exemplars first on the second questionnaire. It was thus possible to test for meaningful order effects at both times. After they had provided attitudes and exemplars for all categories, students were asked to rate the likability of every exemplar they had generated at Time 1 and Time 2 . The students were then thanked and truly debriefed.

\section{Results and Discussion}

\section{Preliminary Analyses}

None of the results to be reported were qualified by an interaction with order of providing attitudes versus exemplars, either on the initial questionnaire or on the final questionnaire. Although far from definitive, the lack of order effects suggests that having students name category exemplars did not induce an artificial decision process, that is, one different from what occurs when people simply assess and report their attitudes.

Similarly, attitude stability (attitude-attitude correlations) averaged .68 across the seven social categories in the control condition and .65 in the experimental condition. The overall probability of naming the same exemplar 1 month apart in the present study was .67 for vegetables and .62 for the seven social categories. These probabilities are similar not only to each other but also to the .69 probability reported earlier for natural-object categories (Bellezza, 1984). These results suggest that the experimental procedure did not alter whatever processes normally occur when people assess and report either attitudes or exemplars.

\section{Attitude Stability}

The primary hypothesis of Experiment 1 was that exemplar stability goes hand-in-hand with attitude stability, at least for social categories. The specific predictions were (a) that students who named the same exemplar for a social category on both questionnaires, 1 month apart, would show greater attitude stability than students who named different exemplars and (b) that individual students would show greater attitude stability for the social categories on which they named the same exemplar than for the social categories on which they named different exemplars.

Table 1 shows the correlations relevant to the first specific prediction. For all seven social categories, attitude-attitude correlations 1 month apart were higher for students who named the same exemplar than for students who named a different exemplar. The difference was individually significant for five of the seven social categories, and all seven were in the predicted direction. Using $r$-to- $z$ transformations, the mean correlation for the seven social categories was .74 for students who named the same exemplar and .53 for students who named different exemplars.

We tested the second specific prediction by comparing the mean absolute difference between the first and second attitudes for the social categories on which a particular student named
Table 1

Attitude-Attitude Correlations (1 Month Apart) for Students Who Spontaneously Named Either the Same or a Different Category Exemplar for Seven Social Categories and One Natural-Object Category, Vegetables (Experiment 1)

\begin{tabular}{lcccccc}
\hline & $\begin{array}{c}\text { Named the } \\
\text { same } \\
\text { exemplar }\end{array}$ & & \multicolumn{2}{c}{$\begin{array}{c}\text { Named a } \\
\text { different } \\
\text { exemplar }\end{array}$} \\
\cline { 2 - 3 } \multicolumn{1}{c}{ Category } & $r$ & $n$ & & $r$ & $n$ & $z$ \\
\hline Politicians & .72 & 82 & .24 & 65 & $3.99^{* *}$ \\
Homosexuals & .92 & 81 & .76 & 66 & $3.31^{* *}$ \\
Televangelists & .69 & 70 & .34 & 68 & $2.83^{* *}$ \\
Talk show hosts & .72 & 89 & .46 & 59 & $2.39^{*}$ \\
Foreign leaders & .72 & 76 & .53 & 71 & $1.97^{*}$ \\
Rock musicians & .67 & 55 & .64 & 93 & 0.34 \\
Comedians & .75 & 89 & .73 & 59 & 0.20 \\
Average social category & .74 & & .53 & & \\
Vegetables & .67 & 60 & .69 & 86 & \\
\hline
\end{tabular}

Note. Numbers of students within a category differ because some students did not provide an exemplar at one of the two assessments. ${ }^{*} p<.05 . \quad{ }^{* *} p<.01$.

the same first exemplar with that value for the sacial categories on which that student named a different first exemplar. The analysis excluded 4 students who named the same first exemplar for all categories and 3 students who named different first exemplars for each of the seven social categories. Attitudes were significantly more stable for the social categories on which students named the same exemplar (mean absolute difference $=$ $1.04, S D=0.82$ ) than for categories on which students named a different exemplar (mean absolute difference $=1.48, S D=$ $1.08), F(1,140)=15.83, p<.001$. These two analyses converged to support the hypothesis that for many social categories, attitude stability is related to exemplar stability.

\section{Individual Differences Versus Category-Specific Factors}

A second research question was whether the tendency to change category exemplars represented a reliable individual difference. Table 2 shows intercorrelations between naming the same exemplar for a category (coded as a 1) and naming a different exemplar (coded as a 2) across the eight categories. As can be seen in the table, the mean intercorrelation (using $r$ to $-z$ transformations) was .02 , and not one of the 28 correlations was significant. Changing exemplars on one category was not related to changing exemplars on other categories. Exemplar stability appears to be a category-specific characteristic rather than a reliable individual difference.

\section{Further Analyses}

Our hypothesis suggested that exemplar stability is related to attitude stability because different members of a social category are more likely to be differently liked than would be the same person at different times. All else being equal, participants who spontaneously named a different social category exemplar at two different times presumably would therefore be more likely to switch to a differently liked person than participants who 
Table 2

Intercorrelations for Naming the Same Versus a Different Exemplar Across Seven Social Categories and One Natural-Object Category, Vegetables (Experiment 1)

\begin{tabular}{lrrrrrrrr}
\hline \multicolumn{1}{c}{ Category } & 1 & 2 & 3 & 4 & 5 & 6 & 7 & 8 \\
\hline 1. Politicians & \multicolumn{1}{c}{ 1 } & & & & & & & \\
2. Televangelists & .08 & - & & & & & \\
3. Talk show hosts & -.03 & .04 & - & & & & \\
4. Foreign leaders & .04 & -.02 & .08 & - & & & \\
5. Homosexuals & -.20 & -.06 & -.01 & .00 & - & & \\
6. Rock musicians & -.02 & .02 & .08 & -.07 & -.04 & - & \\
7. Comedians & .07 & .12 & .08 & .08 & .04 & .11 & - & \\
8. Vegetables & .08 & .05 & .02 & -.02 & .00 & -.05 & .07 & - \\
\hline
\end{tabular}

named the same exemplar would be to like that person differently. For this reason, the reader will recall that each student's categories were chosen for inclusion in the liking ratings because that student named exemplars that pretest participants had regarded as differentially likable by at least 2 scale points, and presumably a differently liked exemplar could have come to mind for that student, with concomitant attitude change. As this attitude change mechanism would predict, the correlation between (a) change in liking for the exemplar named first from Time 1 to Time 2 and (b) change in attitude from Time 1 to Time 2 was significant, $r(146)=.20, p<.05$. One might, however, imagine other category characteristics that could produce this result. Table 3 shows the results for several category characteristics that seemed likely candidates. The categories are listed from left to right in order of the difference between attitude-attitude correlations for students who named the same exemplar and those who named different exemplars; the difference is shown in the top row.

Although the table is far from conclusive, it provides evidence against some reasonable alternative hypotheses. First, the relationship between exemplar stability and attitude stability did not occur only for positive categories or only for negative categories. Second, the difference did not occur only for categories that had either a large or a small standard deviation of initial attitudes. Third, the difference did not occur only for categories that produced either many or few exemplars per student or many or few nonredundant exemplars across students. Fourth, the difference did not occur only for categories in which either a large or a small percentage of students named the same exemplar at Time 2 as at Time 1.

The "Exemplar named" rows of the table suggest a hierarchy such that people are most likely to name the same exemplar that occurred to them initially the first time, followed by either the one that occurred to them second or one they did not name the first time, then the one that occurred to them third, and so on. These rows also seem more encouraging than the top rows for understanding the process by which exemplar stability might be related to attitude stability, but the pattern is not entirely clear. Most of the significant differences occurred for social categories in which students who named different exemplars named their initial second exemplar and not a novel exemplar (one they had not mentioned at Time 1), even when they were

Table 3

Characteristics of the Seven Social Categories and One Natural-Object Category, Vegetables (Experiment 1)

\begin{tabular}{|c|c|c|c|c|c|c|c|c|}
\hline Characteristic & Pol & Tel & Tal & For & Hom & Roc & Com & Veg \\
\hline \multicolumn{9}{|l|}{ Attitude stability difference between students who } \\
\hline \multicolumn{9}{|l|}{ Initial attitude rating } \\
\hline$M$ & -0.63 & -3.24 & 1.95 & -0.43 & -1.22 & 2.42 & 3.12 & 2.50 \\
\hline$S D$ & 2.44 & 2.35 & 2.16 & 2.11 & 2.91 & 2.27 & 1.97 & 2.21 \\
\hline Exemplars per student $(M)$ & 3.5 & 2.2 & 3.8 & 2.8 & 1.8 & 3.2 & 2.9 & 4.1 \\
\hline Nonredundant exemplars $(n)$ & 52 & 14 & 23 & 49 & 41 & 167 & 53 & 47 \\
\hline \multicolumn{9}{|l|}{ Exemplar named ( $\%$ of students) } \\
\hline Same & 57 & 59 & 48 & 52 & 65 & 37 & 60 & 41 \\
\hline Initial 2 & 24 & 20 & 26 & 21 & 11 & 16 & 15 & 14 \\
\hline Initial 3 & 7 & 6 & 6 & 6 & 2 & 7 & 3 & 5 \\
\hline Initial 4 & 1 & 1 & 3 & 1 & 0 & 1 & 3 & 6 \\
\hline Initial 5 & 1 & 1 & 2 & 1 & 0 & 0 & 0 & 2 \\
\hline Initial 6+ & 1 & 0 & 1 & 1 & 0 & 0 & 0 & 0 \\
\hline Novel & 9 & 13 & 14 & 18 & 23 & 39 & 19 & 32 \\
\hline \multirow{2}{*}{\multicolumn{9}{|c|}{ Students who named other student's novel }} \\
\hline & 53 & 32 & 30 & 26 & 15 & 9 & 19 & 11 \\
\hline
\end{tabular}

Note. Pol = politicians; $\mathrm{Tel}=$ televangelists; $\mathrm{Tal}=$ talk show hosts; For $=$ foreign leaders; Hom $=$ homosexuals; Roc $=$ rock musicians; Com $=$ comedians; Veg $=$ vegetables. 
asked to name as many as possible. The attitude stability results, then, do not appear to stem from sudden insights such as "I forgot that Franklin D. Roosevelt was also a politician."' Instead, attitudes changed when people spontaneously thought of other "social category members who were already high on their "response hierarchy" - category members who they had said might come to mind in a different context. Similarly, Asch's (1940) participants presumably knew both the famous president and the infamous Tammany Hall leader and would have named both if pressed to name as many exemplars as possible. Because the percentages for second and novel exemplars are not arrayed in exactly the same order as the attitude stability difference in the top row, however, the conclusions that can be drawn from Table 3 are only speculative. Finally, the bottom row of the table shows that the novel exemplars were rarely unique or unusual exemplars but rather were category members that several other participants had named first on the first questionnaire.

The results displayed in Table 3, then, do not support several reasonable alternative explanations of the relationship between exemplar stability and attitude stability. Instead, the results seem consistent with the hypothesis that thinking about a different exemplar increases the probability of expressing a different attitude. Because students who spontaneously named different, rather than the same, exemplars had less stable attitudes for most of the social categories (and as individuals had less stable attitudes for their "different exemplar" than for their "same exemplar" categories), it seems possible that attitude instability might have led to attitude-behavior inconsistency, which was the hypothesis for Experiment 2.

\section{Experiment 2: Social Category Exemplars and Attitude-Behavior Consistency}

Experiment 2 was similar to Experiment 1, except that it included an assessment of behavioral intentions and actual behavior toward (unspecified members of) two social categories: politicians and homosexuals. Both categories had produced significant attitude stability differences between students who named the same and those who named different exemplars in Experiment 1, and so they seemed good candidates for categories in which we would detect differences in attitude-behavior consistency.

\section{Method}

\section{Participants}

One hundred undergraduates participated for course credit. Data from 7 of the students were not included in the analyses because the students had failed to complete the materials. The final sample included 23 men and 70 women, which was roughly representative of the proportions in the psychology classes from which students were recruited. Gender did not affect the results.

\section{Procedure}

As in the experimental condition of Experiment 1, all students completed an initial questionnaire in one session, made liking ratings in a second session, and completed a second questionnaire in a third session. The procedure for the initial questionnaire was the same as in Experiment 1 , except that the social categories were politicians, homosexuals, tele- vangelists, talk show hosts, foreign leaders, business leaders, and people with AIDS. No natural-object categories were included. Because order had no effect in Experiment 1, all students named the first exemplar that came to mind for each of the categories and then indicated their attitudes toward the categories.

Liking ratings. In the second session, conducted approximately 2 weeks later, a different experimenter collected liking ratings for 150 well-known objects and people, some of which were the politician and homosexual exemplars that each student had provided on the initial questionnaire.

Second questionnaire. In the third session, approximately 1 month after the initial questionnaire, students were again asked to give an exemplar for each category and then asked to indicate their attitude toward the category.

Behavioral measures. After the students had completed the second questionnaire, the session was "interrupted" by a confederate who claimed to have received some petitions and questionnaires from the student council and to want to distribute them in the experiment. The experimenter agreed to let the confederate distribute the materials and then left the room.

The confederate distributed three petitions that urged the university administration to bring more politicians, more homosexuals, and more environmentalists to campus as guest speakers. "Environmentalists" was a filler category. Students were asked to sign whichever petitions they wished, but they were also free to sign none. Signing versus not signing the relevant petitions constituted a dichotomous measure of behavior.

The confederate also asked students to rate on a scale from 0 (not at all willing) to 9 (very willing) the extent to which they were willing to participate in each of 24 different activities to bring (a) politician speakers, (b) environmental speakers, and (c) homosexual speakers to campus. Students were asked to complete the questionnaires honestly because the student council was planning to use these measures to find interested students to help in bringing these groups to campus. Students were told that student council representatives would be calling students the following semester to ask them to participate in any activities in which they had expressed an interest.

The 24 activities were intended to measure various types of behavioral support, such as signing petitions, giving speeches, participating in group activities, writing letters, making phone calls, and getting others to participate in activities. Mean willingness ratings across the 24 activities constituted a measure of behavioral intentions. After the students had completed these measures, the confederate collected the questionnaires and left the room.

After the confederate left, the experiment was "resumed." Students were asked to rate the likability of each exemplar that they had provided either on the initial questionnaire or on the second questionnaire. They were then thanked and debriefed. During debriefing, numerous students spontaneously expressed surprise that they would not be required to fulfill their stated behavioral intentions. Several others spontaneously volunteered that the student council should not be allowed to interrupt ongoing experiments, because such interruptions might invalidate data collection. Even when probed for suspicion about the "real" hypothesis, no student guessed that we were trying to predict, using attitudes on the questionnaire distributed 1 month earlier, the responses on the student council's survey.

\section{Results and Discussion}

One central hypothesis of Experiment 2 was that attitudebehavior consistency would be greater for students who named the same category exemplar 1 month later ("stayers") than for students who named a different category exemplar ("changers"). According to preliminary analyses, stayers had no more 
Table 4

Attitude-Behavioral Intention Correlations and AttitudeBehavior Correlations for Students Who Named Either the Same or a Different Politician Exemplar for Which They Had Either the Same or a Different Liking (Experiment 2)

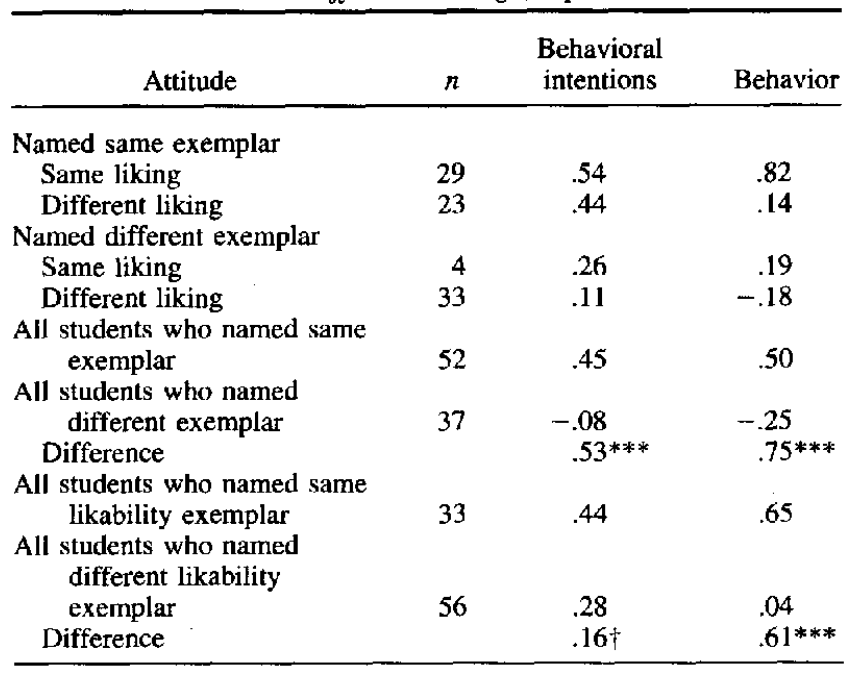

$\dagger p<.10 . \quad * * * p<.001$.

extreme attitudes than did changers toward any of the seven social categories on the initial questionnaire (all $p \mathrm{~s}>.15$ ), which suggests that their attitudes were not more strongly held. Stayers also had no greater correlation between liking for the first-named exemplar and their attitude than did changers (both target category $p s>.15$ ), which suggests that the two types of students were not differentially concerned with presenting themselves as "consistent." Finally, stayers were not more likely than changers to name consensually "popular" first exemplars (both $p s>.15$ ), which suggests that they were not overly concerned with "easy" answers. Differences between stayers and changers in attitude-behavior consistency should be interpreted in light of these nondifferences, all of which might have suggested alternative explanations. A second central hypothesis was that we could predict the direction of attitude-behavior inconsistency by knowing whether changers switched to a more positive or less positive exemplar. Finally, we computed measures of attitude stability to replicate and extend the results of Experiment 1.

\section{Attitude-Behavior Consistency}

Table 4 shows how well students' attitudes toward politicians predicted their behavioral intentions (to write letters, make phone calls, give speeches, participate in group efforts, and engage in other activities aimed at increasing the number of politicians who would visit the campus), as well as their behavior (whether the students signed or did not sign the petition). The table is divided into four pairs of rows to facilitate the relevant comparisons. The top two rows show attitude-behavior correlations for students who named the same politician exemplar on both occasions but either retained or altered their liking for that exemplar. Change in liking was computed as the differ- ence between the liking ratings of Week 2 and the liking ratings at the end of the study. The second pair of rows shows attitudebehavior correlations for students who changed their politician exemplar from the first to the second questionnaire and switched either to an exemplar they liked the same as their initial exemplar or to one they liked differently. The table suggests that either changing to a different but equally likable exemplar or changing one's liking for the same exemplar may reduce attitude-behavior consistency compared with naming the same exemplar and liking that exemplar the same. The only individually significant reduction in attitude-behavior consistency, however, came from changing to a politician exemplar that was both different and differently liked. The comparison between same-same and different-different was marginally significant for behavioral intentions (.54 vs. $.11, z=1.84, p<.07)$ and highly significant for the behavior of signing the petition $(.82$ vs. $-.18, z=4.99, p$ $<.001)$.

The third and fourth pairs of rows in Table 4 allow a more direct comparison of the two variables involved. Collapsing across likability shows that students who named the same politician both times displayed greater attitude-behavior consistency than did those who named different politicians, on both behavioral intentions $(z=3.31, p<.01)$ and signing of the petition $(z=3.56, p<.01)$. Similarly, collapsing across whether the exemplar was the same or different shows that students who did not change the likability of their exemplar displayed marginally greater attitude-behavior consistency than did those who changed likability for behavioral intentions $(z=1.28, p<.10)$ and significantly greater consistency for signing the petition $(z$ $=3.16, p<.01)$.

As shown in Table 5, the other social category, homosexuals, yielded results almost identical to those for politicians. Again, the top two pairs of rows facilitate comparison of the four

Table 5

Attitude-Behavioral Intention Correlations and AttitudeBehavior Correlations for Students Who Named Either the Same or a Different Homosexual Exemplar for Which They Had Either the Same or a Different Liking (Experiment 2)

\begin{tabular}{lccc}
\multicolumn{1}{c}{ Attitude } & $n$ & $\begin{array}{c}\text { Behavioral } \\
\text { intentions }\end{array}$ & Behavior \\
\hline $\begin{array}{l}\text { Named same exemplar } \\
\quad \text { Same liking }\end{array}$ & 17 & .77 & .85 \\
$\begin{array}{l}\text { Different liking } \\
\text { Named different exemplar }\end{array}$ & 23 & .45 & .31 \\
$\quad \begin{array}{l}\text { Same liking } \\
\text { Different liking }\end{array}$ & 9 & .51 & .24 \\
$\begin{array}{l}\text { All students who named same } \\
\quad \text { exemplar }\end{array}$ & 24 & .15 & .14 \\
$\begin{array}{l}\text { All students who named } \\
\quad \text { different exemplar }\end{array}$ & 40 & .59 & .56 \\
$\begin{array}{l}\text { Difference } \\
\text { All students who named same } \\
\quad \text { likability exemplar }\end{array}$ & 33 & -.03 & -.06 \\
All students who named \\
$\quad \begin{array}{l}\text { different likability } \\
\text { exemplar }\end{array}$
\end{tabular}


Table 6

Correlations Between (a) Changes in Students' Liking for the Exemplar They Named First From Time 1 to Time 2 and (b) the Extent to Which Students Behaved More Positively or Less Positively Than Their Initial Attitudes Suggested (Experiment 2)

\begin{tabular}{lcc}
\hline \multicolumn{1}{c}{ Category } & $\begin{array}{c}\text { Named } \\
\text { the same } \\
\text { exemplar }\end{array}$ & $\begin{array}{c}\text { Named } \\
\text { a different } \\
\text { exemplar }\end{array}$ \\
\hline $\begin{array}{l}\text { Politicians } \\
\text { Behavioral intentions }\end{array}$ & .04 & $.53^{*}$ \\
$\begin{array}{l}\text { Behavior } \\
\text { Homosexuals } \\
\quad \text { Behavioral intentions } \\
\text { Behavior }\end{array}$ & .02 & $.64^{*}$ \\
\hline${ }^{*} p .05$. & .05 & .04 \\
\end{tabular}

separate conditions that involved changing or not changing either exemplar or liking. Changing either factor led to moderate attitude-behavior consistency. The comparison between the same exemplar-same liking row and the different exemplardifferent liking row was significant for both behavioral intentions $(.77$ vs. $.15, z=2.67, p<.001)$ and the behavior of signing the petition $(.85$ versus $.14, z=3.42, p<.001)$. The bottom two pairs of rows show that either change in exemplar (collapsed across liking) or change in liking (collapsed across whether the exemplar changed or not) significantly reduced attitude-behavior consistency, both for behavioral intentions (exemplar change $z=2.94, p<.() 1$; liking change $z=3.44, p<$ .01 ) and for signing the petition (exemplar change $z=2.85, p$ $<.01$; liking change $z=3.01, p<.01$ ). Exemplar stability, then, seemed as related to attitude-behavior consistency as it had been to attitude stability in Experiment 1.

\section{Direction of Behavioral Inconsistency}

In addition to predicting that greater exemplar instability would be associated with lower attitude-behavior consistency, Experiment 2 was designed to test whether it was possible to predict the direction of behavioral inconsistency from the direction of exemplar change. Did students who thought of a more likable politician or homosexual on the second than on the first questionnaire behave more positively than would have been predicted from their initial questionnaire attitudes, and did students who thought of a less likable politician or homosexual on the second than on the first questionnaire behave more negatively than would have been predicted from their initial questionnaire attitudes?

To answer this question, we subtracted each student's liking rating for the first questionnaire politician or homosexual exemplar (obtained from the "unrelated" liking ratings) from that student's liking rating for the second questionnaire politician or homosexual exemplar (obtained at the end of the study). The resulting difference score was correlated with a second difference score that represented the difference between the (standardized) initial attitude and the (standardized) willingness to support politicians or homosexuals on the behavioral intention and signing measures. As shown in Table 6, changing to a more positive or less positive exemplar significantly predicted whether a student would behave either more or less positively toward politicians or homosexuals than his or her initial attitude would have suggested. The correlations were significant for both the politician category and the homosexual category, but only for students who named a different exemplar. Liking the same exemplar differently was not related to behaving more positively or less positively than expected. It is only when a different and differentially likable exemplar comes to mind, therefore, that people behave in a systematically more positive or less positive way than their initial attitudes might have suggested.

\section{Direction of Attitude Instability}

Finally, from the data, it was also possible to compute the same measures of attitude stability as were computed for Experiment 1 . The attitude stability results for the seven social categories of Experiment 2 were very similar to those reported for Experiment 1. Attitude stability was significantly greater for students who named the same rather than a different exemplar for politicians ( $r \mathrm{~s}=.91$ vs. $.44, z=4.79, p<.01$ ), homosexuals ( $r \mathrm{~s}=.88$ vs, $.44, z=3.76, p<.01)$, televangelists $(r \mathrm{~s}=$ .76 vs. $.47, z=2.29, p<.05)$, and foreign leaders $(r \mathrm{~s}=.70$ vs. $.36, z=2.26, p<.05)$. The difference was marginally significant for business leaders $(r s=.75$ vs. $.52, z=1.88, p$ $<.10$ ) and for people with AIDS ( $r \mathrm{~s}=.73$ vs. $.44, z=1.80$, $p<.10$ ) and was in the predicted direction but not significant for talk show hosts ( $r \mathrm{~s}=.70 \mathrm{vs} .53, z=1.26$ ). Across seven social categories, the mean attitude-attitude correlation was .80 for students who named the same exemplar and .44 for students who named different exemplars. Also, individual students had more stable attitudes toward the categories on which they named the same exemplar (mean absolute difference $=0.98, S D=$ 0.61 ) than toward the categories on which they named a different exemplar (mean absolute difference $=1.74, S D=1.15$ ), $F(1,88)=33.75, p<.0001$.

Finally, the direction of change in exemplar liking predicted the direction of spontaneous attitude change from Time 1 to Time 2. As shown in Table 7, change in liking for the exemplar

\section{Table 7}

Correlations Between (a) Changes in Students' Liking for the Exemplar They Named First From Time 1 to Time 2 and (b) the Extent to Which Students Reported More Positive or Less Positive Attitudes at Time 2 Than at Time 1 (Experiment 2)

\begin{tabular}{lccccc}
\hline & \multicolumn{2}{c}{$\begin{array}{c}\text { Named } \\
\text { the same } \\
\text { exemplar }\end{array}$} & & \multicolumn{2}{c}{$\begin{array}{c}\text { Named } \\
\text { a different } \\
\text { exemplar }\end{array}$} \\
\cline { 2 - 5 } \multicolumn{1}{c}{ Category } & $r$ & $n$ & & $r$ & $n$ \\
\hline Politicians & -.03 & 54 & $.48^{* *}$ & 38 \\
Homosexuals & -.05 & 40 & $.32^{* *}$ & 34 \\
Televangelists & .13 & 48 & $.52^{* *}$ & 29 \\
Foreign leaders & .01 & 40 & $.52^{* *}$ & 45 \\
Talk show hosts & .13 & 47 & $.36^{* *}$ & 40 \\
Business leaders & .09 & 50 & $.33^{* *}$ & 32 \\
People with AIDS & $.22^{*}$ & 67 & $.21^{* *}$ & 23 \\
\hline
\end{tabular}

${ }^{*} p<.05 . \quad * * p<.01$. 
students named first on the initial questionnaire to liking for the exemplar they named first on the second questionnaire was significantly correlated with change in attitude toward the category for students who named different exemplars, but (with one exception) not for students who named the same exemplar. These results seem consistent with Asch's (1940) findings about changes in social category attitudes as a function of the exemplars that come to mind.

\section{Experiment 3: Using Social Category Exemplars to Change Attitudes}

Although Experiments 1 and 2 provided evidence for exemplar stability as a category-specific individual difference that plays an important role in attitude-behavior consistency and attitude change, the results were correlational and did not address causality. The exemplar perspective is that attitudes and other "mental representations" are not things that are stored and later retrieved unchanged, but rather states that are intrinsically dynamic and influenced by the temporary context (Smith, in press). When a category is to be evaluated, different subsets of exemplars come to mind in different contexts. Different types of birds come to mind in a suburban backyard, for instance, than in a barnyard (Carlston \& Smith, 1996; Smith, in press). According to the exemplar perspective, then, unstable exemplars can cause attitudes to become more positive or more negative from one time to the next. If the exemplar perspective is correct, it should be possible to manipulate social category attitudes by rendering a more positive or a more negative exemplar temporarily accessible.

The most relevant published study concerned atypical exemplars and racial attitudes (Bodenhausen et al., 1995). The researchers reminded students of well-liked, successful African Americans. In Experiment 1, students rated several target persons as role models for success and achievement. In Experiment 2 , students estimated the height of several target persons. In both experiments, the last target person rated was either a White person (like all the others), Oprah Winfrey, or Michael Jordan. After an intervening filler task, the same students indicated their belief that "discrimination against Blacks is no longer a significant problem in the U.S." (Bodenhausen et al., 1995, p. 53). In both experiments, students were more likely to view discrimination against Blacks as a problem when they had recently rated Winfrey or Jordan than when they had not. When the last person was a Black person that the average pretest participant had rated as neutral rather than positive, such as Spike Lee or Jesse Jackson, views on discrimination were not affected. Although no attitude measures were taken, the researchers interpreted their results as consistent with a conceptual model in which recently " activated" positive exemplars temporarily altered attitudes toward African Americans, which were manifested in greater belief that discrimination is a current societal problem.

In a second experiment, the authors showed that the effect was due not to students having rated the target persons on a positive dimension but rather to sheer accessibility. They replicated their results by having students estimate the height of positive exemplars, a nonevaluative dimension presumably unrelated to prestige or respect. Although the results of Bodenhausen et al.'s (1995) experiments were encouraging (especially Exper- iment 2 , where estimates of height merely made the positive exemplars more accessible and avoided possible contrast effects from considering them as role models), these results did not directly address the present concerns about a possible causal relationship between exemplar change and attitude change. To do so, we conducted a third experiment in which we measured initial attitudes toward politicians, then used Bodenhausen et al.'s (1995, Experiment 2) accessibility manipulation to remind participants of a specific politician, and then finally remeasured attitudes.

\section{Method}

\section{Participants}

Fifty-three undergraduates ( 12 men and 41 women) participated for course credit. As in the other studies, gender did not affect the results.

\section{Procedure}

In Session 1, students provided their attitudes toward and generated exemplars for 27 social categories, including politicians, as described in Experiments 1 and 2. In Session 2, approximately 2 weeks later in a different setting with a different experimenter, the same students completed liking scales that included several politicians, as described in Experiments 1 and 2. From these liking ratings, we identified one politician that the student liked better and one that the student liked worse than the politician that the student had earlier named as first exemplar.

In Session 3, approximately 4 weeks after the initial attitude questionnaire and 2 weeks after the "unrelated" liking scales, eligible students (who had at least one politician that they liked more and one that they liked less than the one they named first on the initial attitude questionnaire ) participated in two tasks that were presented as unrelated experiments. In the first task, students estimated the height of 10 famous target persons, the first 9 of whom were nonpoliticians. Depending on which of the three groups to which a student was randomly assigned, the 10th person was either the same politician the student had named first on the initial attitude questionnaire, another politician that the student had named but regarded as less likable, or yet another politician that the student had named but regarded as more likable. In the second task, after changing experimenters and completing a new consent form for a "different" study, all students reported again their attitudes toward 27 social categories, the 6th of which was politicians.

When students were subsequently debriefed, they were asked to guess each experiment's hypothesis. No student correctly guessed that we were trying to alter their attitudes toward politicians by using the height estimates to remind them of a specific politician.

\section{Results}

The experiment's central hypothesis was that students who were reminded of the same exemplar that they had named previously would retain their earlier attitudes, whereas students who were reminded of a different exemplar from the initial questionnaire would change their attitudes in the predicted directions. The results, shown in Table 8, confirmed these predictions. In a 3 (reminded of less likable, same, or more likable politician) $\times 2$ (Time 1 or Time 2) analysis of variance (ANOVA), the two-way interaction was significant, $F(2,50)=4.34, p<.05$. Attitudes did not differ across the three conditions on the initial attitude questionnaire ( $F$ $<1$ ), but they did differ on the questionnaire completed after the height estimation task, $F(1,50)=3.53, p<.05$. In addition, 
Table 8

Mean Pre-and Postmanipulation Attitudes for Students Who, Before the Second Attitude Measurement, Estimated the Height of the Same Politician They Had Named at Time 1, a Politician They Liked More, or a Politician They Liked Less (Experiment 3)

\begin{tabular}{|c|c|c|c|c|c|c|}
\hline \multirow{3}{*}{$\begin{array}{c}\text { Attitude } \\
\text { measurement time }\end{array}$} & \multicolumn{6}{|c|}{ Exemplar of whom student was reminded } \\
\hline & \multicolumn{2}{|c|}{$\begin{array}{l}\text { Less likable politician } \\
\qquad(\mathrm{n}=20)\end{array}$} & \multicolumn{2}{|c|}{$\begin{array}{l}\text { Same politician } \\
\qquad(\mathrm{n}=18)\end{array}$} & \multicolumn{2}{|c|}{$\begin{array}{l}\text { More likable politician } \\
\qquad(\mathrm{n}=15)\end{array}$} \\
\hline & Mean attitude & $S D$ & Mean attitude & $S D$ & Mean attitude & $S D$ \\
\hline Time 1 & -0.75 & 1.83 & -0.83 & 1.86 & -0.40 & 2.41 \\
\hline Time 2 & -2.15 & 2.60 & -0.83 & 2.09 & 0.40 & 3.74 \\
\hline
\end{tabular}

using premanipulation attitudes as the covariate in an analysis of covariance, we found that the three postmanipulation attitudes were reliably different, $F(2,49)=4.46, p<.05$.

\section{General Discussion}

The results of the present experiments demonstrate the potential importance of spontaneous, or induced, exemplar change in predicting and explaining attitude-behavior inconsistency. Experiment 1 showed that sometimes different exemplars spontaneously come to mind for social categories, much as they do for natural-object categories. When a different exemplar comes to mind, it is most likely to be the one they had named second. When a previously unmentioned exemplar comes to mind, it is likely to be one that other people had previously named firstan exemplar that it seems reasonable to assume they knew but "forgot" the first time.

Experiment 1 also showed that attitudes are more stable for people for whom the same exemplar of a social category comes to mind at different times than for people for whom different exemplars come to mind, and that individuals have more stable attitudes toward social categories for which the same exemplar comes to mind than toward social categories for which different exemplars come to mind. Naming a different exemplar was a category-specific characteristic rather than an individual difference. In addition, the relationship between exemplar stability and attitude stability could not be explained by initial attitude positivity, initial attitude variance, mean number of exemplars per student, number of nonredundant exemplars across students, or the percentage of students who named the same exemplar 1 month apart. The relationship was most evident for categories in which participants who did change exemplars named their second, rather than a previously unnamed, exemplar.

Experiment 2 replicated the major findings from Experiment 1 and extended these results to show that changing exemplars also has a predictable effect on attitude-behavior consistency and that, for students who had a different exemplar come to mind at Time 2 than at Time 1 , the direction of change in exemplar liking predicted whether students behaved in ways that were either more or less positive than would have been predicted from their initial attitudes. Merely changing the exemplar or merely changing liking for the exemplar did not have the same effect as changing both the exemplar and liking. Planned comparisons showed that students who named the same exem- plar and liked that exemplar the same had significantly greater attitude-behavior consistency than did students who named a different exemplar that they liked differently.

Although participants always named a category exemplar first and assessed their own attitudes second in Experiment 2, the lack of order effects in Experiment 1 suggested that attitudes and exemplars of social categories may be part of a "spreading activation" network (e.g., Collins \& Loftus, 1975). Thinking about one's attitude toward politicians may spontaneously elicit thoughts of Bill Clinton. Conversely, thinking about Bill Clinton may spontaneously elicit one's attitude toward politicians. The attitude stability coefficients for the experimental condition of Experiment 1 were very similar to the results for a control group that was not asked to name category exemplars. The probability of naming the same, rather than a different, social category exemplar was also very similar to previous probabilities reported for natural-object categories. The results of Experiments 1 and 2, therefore, may reflect the "normal" process that underlies attitudes and thus may offer insights into why attitudes sometimes predict and at other times do not predict behaviors toward negatively stigmatized minority groups and other social categories.

Finally, Experiment 3 established a causal relationship between being reminded of a specific social category exemplar and attitudes toward that category. According to the exemplar perspective (Smith, 1996), attitudes and other mental representations are temporary constructions that differ from one time to the next as different subsets of exemplars become activated. Consistent with results of previous research on the exemplar mechanism, students who had recently estimated the height of the politician exemplar they had named first on a questionnaire completed 1 month earlier retained exactly the same mean attitudes ( to two decimal places) from one month to the next. Also, students who had recently estimated the height of a politician they found more likable than the one they had named first reported more positive attitudes toward politicians in general than did students who had recently estimated the height of a politician they found less likable. The combined results of Experiments 1-3 thus have implications for both attitude measurement and attitude theory.

\section{Implications for Measuring Attitudes}

In 1934, Richard LaPiere noted that answers to an attitude questionnaire constitute verbal responses to a symbolic situa- 
tion. The present studies suggest that it might be useful to measure the symbolic representation of an attitude object in greater detail. This suggestion fits well with recent advances in attitude measurement. Esses, Haddock, and Zanna (1994), for instance, developed a technique for measuring separately the three traditional components of attitude: the affective, behavioral, and cognitive components. To measure the affective component, they ask participants to list the emotions that the attitude object elicits. "'Politicians," for example, might elicit for a disaffected individual the emotions anger, disgust, and sadness. To measure the behavioral component, they ask participants to list their own behaviors toward the attitude object (e.g., "signed petitions for term limits," "voted against incumbents"). To measure the cognitive component, they ask participants to list the characteristics they associate with the attitude object (e.g., "dishonest," "smooth-talking"'). After listing whatever emotions, behaviors, and characteristics come to mind, participants rate each item on their spontaneously generated lists for its positivity or negativity. These ratings, together with an overall attitude assessment, allow researchers to calculate each individual participant's reliance on each of the three components.

Esses et al.'s (1994) measurement technique is similar to the procedure used in the present experiments in that it elicits spontaneous responses rather than relying on the experimenter's intuitions about which dimensions might be important. Likewise, Eagly, Mladinic, and Otto (1994) independently developed a way to measure the affective and cognitive attitude components that also relies on spontaneously generated, rather than experimenter-defined, dimensions. The contribution of the present experiments is to suggest that spontaneously named exemplars might be included as part of such a measurement technique. Although it seems likely that spontaneously named social category exemplars would be most closely associated with the cognitive component of attitudes as measured by Esses et al.'s procedure, this possibility could be subjected to an empirical test.

Naming specific exemplars might not prove a feasible measurement technique for all social categories. Some social categories, perhaps even "'members of the Chinese race," for some of the proprietors in LaPiere's (1934) study, might be represented not by specific exemplars but rather by an abstraction or a caricature. Social category exemplars, that is, might include a " 'representation of a 'typical member of Group X' constructed on the basis of reflection about the group's general characteristics, a secondhand description of the group, or a joke or slur that implies the group possess some stereotypical attribute" (Smith, in press). Previous research has shown that people who say they have an abstraction in mind for a social category have attitudes that are more amenable to change through pleasant contact with a category member than do people who say they have a specific exemplar in mind (Werth \& Lord, 1992); hence, identifying the participants who spontaneously name and those who do not name specific exemplars may prove useful in study ing attitudes. For some social category attitudes (e.g., "the homeless"'), however, the only exemplar for most individuals might be an abstraction. The present procedure of naming specific exemplars would not be appropriate for investigating the stability of such categories.

The measurement technique of asking participants to name exemplars might prove useful, however, for investigating some attitudes toward other than social categories. Lord, Desforges, Fein, Pugh, and Lepper (1994) showed that some attitudes toward social policies entail thoughts about category exemplars. In one of their studies, many students who had either positive or negative attitudes toward the welfare system drew spontaneous "attitude concept maps" ( starting from a central node labeled "welfare" in the middle of a blank page) that emphasized the characteristics of welfare recipients. Students who emphasized recipients (exemplars) in their attitude concept maps were also more likely than their peers to display greater attitude-behavior consistency toward a typical than toward an atypical welfare mother. In another of Lord et al.'s (1994) studies, specific murderers such as Charles Manson and Ted Bundy spontaneously appeared in the "capital punishment" maps of death penalty proponents but not death penalty opponents. As predicted, proponents displayed greater attitude-behavior consistency in hypothetically sentencing typical versus atypical convicted murderers, whereas opponents did not. Even for attitudes toward social policies, then, it might be informative to include in Esses et al.'s (1994) measurement technique a request to list not only characteristics but also (where possible) specific exemplars.

A final measurement observation is that it might prove useful to have participants in attitude studies generate their social category exemplars on computers, where the investigators could record not only which exemplars came to mind but how rapidly each exemplar came to mind. Fazio (1990) and his colleagues have shown convincingly that relatively accessible attitudes predict behavior better than do relatively inaccessible attitudes. Their measurement technique is to ask participants whether the attitude object has various positive or negative characteristics, such as "pleasant" or "undesirable." Individuals who answer these questions rapidly have relatively accessible attitudes that come to mind spontaneously when they encounter the attitude object. In one study, for instance, people who were relatively quick to answer such questions about "politicians" were also more likely to vote in line with their stated attitudes (Fazio \& Williams, 1986).

A similar reaction time measure might be applied to spontaneously generating social category exemplars. Through such a measurement technique, one could assess whether exemplar accessibility has the same effects as overall attitude accessibility. It might, or it might not. Schwarz et al. (1991), for instance, argued that accessibility and availability are separate constructs. Availability has to do with the amount of information. Accessibility has to do with the subjective ease of retrieving information. A student may know (have available) the names of many politicians, but only a few of them may come easily to mind (be accessible) at any given time. Schwarz et al. misled participants about how accessible instances of their own behavior were by asking them to name only a few (which felt easy) or many (which felt difficult). Although all participants had the instances available, perceived accessibility influenced inferences that they drew about their own personalities. It is possible, then, that a similar procedure of making social category exemplars seem relatively accessible or inaccessible might affect people's inferences about their own attitudes, with corresponding effects on attitude stability, attitude-behavior consistency, or both. At the very least, it would be interesting to separate availability from 
accessibility in measuring the relationship between social category exemplars and attitudes.

\section{Theoretical Implications}

The present findings are consistent with several theoretical suggestions about the nature of attitudes and attitude-behavior consistency. First, the findings for attitude stability support and extend Wilson and Hodges's (1992) suggestions about the consequences of introspecting on reasons for holding an attitude. In a program of studies, Wilson and his associates have amassed considerable evidence that some attitudes are "temporary constructions," related to whichever piece of relevant information comes to mind ( see also Tesser, 1978). Wilson, Kraft, and Dunn (1989), for instance, asked students to introspect about their reasons for liking or disliking various politicians, after which some students reported more positive attitudes than they previously had expressed, whereas others reported more negative attitudes than they previously had expressed. Across such studies, students who predominantly generated reasons for holding a positive attitude adopted more positive attitudes, whereas those who predominantly generated reasons for holding a negative attitude adopted more negative attitudes (Wilson, Lisle, \& Schooler, 1990). The present study suggests that people for whom more positive exemplars spontaneously come to mind are likely to adopt more positive attitudes, whereas people for whom more negative exemplars spontaneously come to mind are likely to adopt more negative attitudes. The general principle supported by both Wilson's and the present studies is that attitudes often fluctuate according to which part of the large and sometimes conflicting database is salient at the time (see also Smith, 1996).

It would be interesting to investigate the factors that determine whether, and if so which, category exemplars come to mind when people consider their attitude toward or have an opportunity to behave toward a social category. In Asch's (1940) study, the deciding factor was probably peer opinion. When they learned that 500 peers had rated politicians very positively, for instance, students may have inferred that their peers took politicians to mean statespersons, whereas when they learned that 500 peers had rated politicians very negatively, they may have inferred that their peers took politicians to mean party hacks. Another important factor in making one, rather than another, social category exemplar salient might be frequency of exposure, perhaps via media coverage. In 1984, Lord et al. speculated that "this is one way in which a Martin Luther King, for example, can have a positive effect on race relations. Sufficient exposure to King may have caused millions of Americans to picture him, perhaps in the act of delivering his famous 'I have a dream' speech, whenever they thought of blacks"' ( $p$. 1264). In 1993, Graham, Weiner, Giuliano, and Williams showed that public opinion toward people with AIDS changed for the better immediately after Magic Johnson announced that he had the deadly disease. The present study and the Graham et al. study thus suggest at least one mechanism through which a specific part of the database relevant to an attitude might change from one time to the next, with predictable consequences for attitude stability, attitude-behavior consistency, and attitude change. The mechanism involves adding a new member to a category who receives such widespread publicity that he or she becomes the most salient category member "overnight." Along these lines, it is interesting to speculate as well on what happens when a previously salient exemplar ( such as Pete Rose for baseball players or Jim Bakker for televangelists ) changes greatly in likability. Do people have the same exemplar come to mind but change their attitude toward the category, or do they have a different exemplar come to mind and retain their initial attitude?

On a more general level, the present study supports previous suggestions that attitude-behavior consistency depends in part on a match, rather than a mismatch, between how the attitude object is represented and how the behavior target is represented. In Ajzen and Fishbein's (1977, 1980) specificity-matching model of attitude-behavior consistency, for example, attitudes predict behavior better when the attitude and the behavior are measured at the same, rather than at a different, level of specificity. Attitudes toward the Sierra Club (specific attitudes), for instance, are more likely than attitudes toward the environment (general attitudes) to predict helping the Sierra Club (a specific behavior; Weigel, Vernon, \& Tognacci, 1974). Similarly, Millar and Tesser's (1992) mismatch hypothesis is that attitudes based primarily on the affective component predict affectively laden (consumatory) behavior, whereas attitudes based primarily on the cognitive component predict cognitively mediated (instrumental) behavior. In both Ajzen and Fishbein's and Millar and Tesser's models, attitude-behavior consistency requires a match between how the attitude object is represented and how the behavior target is represented, just as in the present Experiment 2 , attitude-behavior consistency was greater when participants had in mind the same exemplar at Time 1 as at Time 2.

Although the traditional model suggests that attitude representations involve three components, this is not the only way that an attitude object might be represented (Eagly \& Chaiken, 1993). According to associated systems theory (Carlston, 1994), for instance, persons might be represented in four, rather than three, systems: an affective system, a behavioral system, a verbal system, and a visual system. The affective, behavioral; and verbal systems are roughly equivalent to the affective, behavioral, and cognitive systems of the traditional three-component theory, but the visual system might easily be involved in representing an attitude object if the attitude object is a social category. In a relevant study, Lord et al. (1991) created a novel social category "from scratch" in the laboratory through a category-formation task that involved differences between members and nonmembers in hairstyle and color. Subsequently, student participants behaved more in line with their attitudes toward a specific member who had the typical, rather than an atypical, hairstyle and color, even though physical appearance had nothing to do with why they harbored positive or negative attitudes toward the group. It would be interesting to know which affects attitude-behavior consistency most-misfits in the affective, behavioral, cognitive, or visual systems-and whether, when it comes to attitude-behavior consistency, the four types of representation interact in ways derived from associated systems theory.

A considerable aid in pursuing these theoretical objectives might come from integrating the present work with Smith and Zarate's (1992) social judgment theory. According to social judgment theory, people evaluate and make decisions about new 
instances of a social category by comparing each new instance to a known category exemplar, which is generated spontaneously. The generation of specific exemplars can occur without conscious awareness, is sometimes more efficient than trying to conceptualize the entire category, depends on the perceiver's goal of the moment as well as the ever-changing social context, and is influenced by the perceiver's past experiences (Smith, 1992; Zarate \& Smith, 1990). Similarly, participants in the present study may not have realized that they thought about specific exemplars when assessing their attitudes or deciding how to behave. Exemplars such as Bill Clinton may have come to mind very rapidly and may have come to mind more when participants were pursuing one goal (e.g., assessing attitude toward politicians) than when they were pursuing other goals (e.g., defining politicians). These possibilities are worth pursuing in future efforts to understand how social category exemplars relate to social category attitudes.

In the social judgment model, in addition, frequently encountered exemplars become more accessible and more likely to be generated and to influence judgments. The politician exemplars that students in the present studies named were probably frequently encountered, albeit indirectly through the media. Exemplar instability might have occurred in part because the media made one or another politician temporarily more accessible. An individual who watched television sessions of the United States Senate, for example, might be unlikely to generate a female politician exemplar when asked to make a decision about politicians because very few senators are women. Smith and Zarate's (1992) work on the social judgment model thus affords a richly developed, conceptually grounded set of procedures that are directly applicable to studying how the representation of an attitude object might differ from the representation of a behavior target. In other words, researchers have available today a wide range of procedures that allow a more in-depth analysis of the two "symbolic situations" than were available to LaPiere (1934) and Asch (1940) when they advanced their prescient ideas some 60 years ago.

Gertrude Stein's famous dictum, "A rose is a rose is a rose," may be a fine description for understanding most people's attitudes toward flowers. When the putative object is instead a diverse social category such as politicians or homosexuals, however, the case is necessarily more complex: The category "politicians" may bring to mind a Roosevelt at one time and a Boss Tweed at another time, even for the same individual. And that difference is one that clearly makes a difference.

\section{References}

Ajzen, 1., \& Fishbein, M. (1977). Attitude-behavior relations: A theoretical analysis and review of empirical research. Psychological Bulle. tin, 84, 888-918.

Ajzen, I., \& Fishbein, M. (1980). Understanding attitudes and predicting social behavior. Englewood Cliffs, NJ: Prentice Hall.

Alwin, D. F. (1976). Making inferences from attitude-behavior correlations. Sociometry, 36, 253-278.

Asch, S. E. (1940). Studies in the principles of judgments and attitudes: II. Determination of judgments by group and by ego standards. Journal of Social Psychology, SPSSI Bulletin, 12, 433-465.

Bellezza, F. S. V. (1984). Reliability of retrieval from semantic memory: Common categories. Bulletin of the Psychonomic Society, 22, 324326.
Biernat, M., \& Manis, M. (1994). Shifting standards and stereotypebased judgments. Journal of Personality and Social Psychology, 66 , 5-20.

Bodenhausen, G. V., Schwarz, N., Bless, H., \& Wănke, M. (1995). Effects of atypical exemplars on racial beliefs: Enlightened racism or generalized appraisais? Journal of Experimental Social Psychology, $31,48-63$.

Carlston, D. E. (1994). Associated systems theory: A systematic approach to cognitive representations of persons. In R. S. Wyer (Ed.), Advances in social cognition (Vol. 7, pp. 1-78). Hillsdale, NJ: Erlbaum.

Carlston, D. E., \& Smith, E. R. (1996). Principles of mental representation. In E. T. Higgins \& A. W. Kruglanski (Eds.), Social psychology: Handbook of basic principles (pp. 184-210). New York: Guilford.

Collins, A. M., \& Loftus, E. F. (1975). A spreading activation theory of semantic processing. Psychological Review, 82, 407-428.

Eagly, A. H., \& Chaiken, S. (1993). The psychology of attitudes. New York: Harcourt Brace Jovanovich.

Eagly, A. H., Mladinic, A., \& Otto, S. (1994). Cognitive and affective bases of attitudes toward social groups and social policies. Journal of Experimental Social Psychology, 30, 113-137.

Esses, V. M., Haddock, G., \& Zanna, M. P. (1994). The role of mood in the expression of intergroup stereotypes. In M. P. Zanna \& J. M Olson (Eds.), The psychology of prejudice: The Ontario symposium (Vol. 7, pp. 77-101). Hillsdale, NJ: Erlbaum

Fazio, R. H. (1990). Multiple processes by which attitudes guide behavior: The MODE model as an integrative framework. In M. P. Zanna (Ed.), Advances in experimental social psychology (Vol. 23, pp. 75110). New York: Academic Press.

Fazio, R. H., \& Williams, C. J. (1986). Attitude accessibility as a moderator of the attitude-perception and attitude-behavior relations: An investigation of the 1984 presidential election. Journal of Personality and Social Psychology, 51, 505-514.

Fishbein, M. (1976). Attitude and the prediction of behavior. In M. Fishbein (Ed.), Readings in attitude theory and measurement (pp. 477-492). New York: Wiley.

Graham, S., Weiner, B., Giuliano, T., \& Williams, E. (1993). An attributional analysis of reactions to Magic Johnson. Journal of Applied Social Psychology, 23, 996-1010.

LaPiere, R. T. (1934). Attitudes versus actions. Social Forces, 13, 230237.

Lord, C. G., Desforges, D. M., Fein, S., Pugh, M. A., \& Lepper, M. R. (1994). Typicality effects in attitudes toward social policies: A concept-mapping approach. Journal of Personality and Social Psychology, 66, 658-673.

Lord, C. G., Desforges, D. M., Ramsey, S. L., Trezza, G. R., \& Lepper, M. R. (1991). Typicality effects in attitude-behavior consistency: Effects of category discrimination and category knowledge. Journal of Experimental Social Psychology, 27, 550-575.

Lord, C. G., Lepper, M. R., \& Mackie, D. (1984). Attitude prototypes as determinants of attitude-behavior consistency. Journal of Persunality and Social Psychology, 46, 1254-1266.

Millar, M. G., \& Tesser, A. (1992). The role of beliefs and feelings in guiding behavior: The mismatch model. In L. L. Martin \& A. Tesser (Eds.), The construction of social judgments (pp. 277-300). Hillsdale, NJ: Erlbaum.

Ramsey, S. L., Lord, C. G., Wallace, D. S., \& Pugh, M. A. (1994). The role of subtypes in attitudes towards superordinate social categories. British Journal of Social Psychology, 33, 387-403.

Salancik, J. R., \& Conway, M. (1975). Attitude inferences from salient and relevant cognitive content about behavior. Journal of Personality and Social Psychology, 32, 829-840.

Schuman, H., \& Johnson, M. P. (1967). Attitudes and behavior. Annual Review of Sociology, 2, 161-207. 
Schwartz, S. H. (1978). Temporal instability as a moderator of the attitude-behavior relationship. Journal of Personality and Social Psychology, 30, 715-724.

Schwartz, S. H., \& Tessler, R. C. (1972). A test of a model for reducing measured attitude-behavior discrepancies. Joumal of Personality and Social Psychology, 24, 225-236.

Schwarz, N., \& Bless, H. (1992a). Constructing reality and its alternatives: An inclusion/exclusion model of assimilation and contrast effects in social judgment. In L. L. Martin \& A. Tesser (Eds.), The construction of social judgments (pp. 217-245). Hillsdale, NJ: Erlbaum.

Schwarz, N., \& Bless, H. (1992b). Scandals and the public's trust in politicians: Assimilation and contrast effects. Personality and Social Psychology Bulletin, 18, 574-579.

Schwarz, N., Bless, H., Strack, F., Klumpp, G., Rittenauer-Schatka, H., \& Simmons, A. (1991). Ease of retrieval as information: Another look at the availability heuristic. Joumal of Personality and Social Psychology, 61, 195-202.

Smith, E. R. (1992). The role of exemplars in social judgment. In L. L. Martin \& A. Tesser (Eds.), The construction of social judgments (pp. 37-65). Hillsdale, NJ: Erlbaum.

Smith, E. R. (in press). Mental representation and memory. In G. Lindzey, S. T. Fiske, \& D. Gilbert (Eds.), Handbook of social psychology (4th ed.). New York: McGraw-Hill.

Smith, E. R., \& Zarate, M. A. (1990). Exemplar and prototype use in social categorization. Social Cognition, 8, 243-262.

Smith, E. R., \& Zarate, M. A. (1992). Exemplar-based model of social judgment. Psychological Review, 99, 3-21.

Tesser, A. (1978). Self-generated attitude change. In L. Berkowitz (Ed.), Advances in experimental social psychology (Vol. 11, pp. 289-338). San Diego, CA: Academic Press.
Thurstone, L. L. (1931). The measurement of attitudes. Journal of $A b-$ normal and Social Psychology, 26, 249-269.

Weigel, R. H., Vernon, D. T. A., \& Tognacci, L. N. (1974). Specificity of the attitude as a determinant of attitude-behavior congruence. Joumal of Personality and Social Psychology, 30, 724-728.

Werth, J. L., \& Lord, C. G. (1992). Previous conceptions of the typical group member and the contact hypothesis. Basic and Applied Social Psychology, 13, 351-369.

Wicker, A. W. (1969). Attitudes versus actions: The relationship of verbal and overt behavioral responses to attitude objects. Journal of Social Issues, 25, 41-78.

Wilson, T. D., \& Hodges, S. D. (1992). Attitudes as temporary constructions. In L. L. Martin \& A. Tesser (Eds.), The construction of social judgments (pp. 37-65). Hillsdale, NJ: Erlbaum.

Wilson, T. D., Kraft, D., \& Dunn, D. S. (1989). The disruptive effects of explaining attitudes: The moderating effect of knowledge about the attitude object. Journal of Experimental Social Psychology, 25, 379-400.

Wilson, T. D., Lisle, D. J., \& Kraft, D. (1990). Effects of self-reflection on attitudes and consumer decisions. Advances in Consumer Research, 17, 79-85.

Wilson, T. D., Lisle, D. J., \& Schooler, J. (1990). Some undesirable effects of self-reflection. Unpublished manuscript, University of Virginia, Charlottesville.

Zanna, M. P., \& Rempel, J. K. (1988). Attitudes: A new look at an old concept. In D. Bar-Tal \& A. W. Kruglanski (Eds.), The social psychology of knowledge (pp. 315-334). Cambridge, England: Cambridge University Press.

Zarate, M. A., \& Smith, E. R. (1990). Person categorization and stereotyping. Social Cognition, 8, 161-185.

Received August 21, 1995

Revision received June 13, 1996

Accepted June 27, 1996 